\title{
Landscape of antimicrobial stewardship programs in Ontario: a survey of hospitals
}

\author{
Valerie Leung BScPhm MBA, Julie Hui-Chih Wu MSc, Bradley J. Langford BScPhm PharmD, \\ Gary Garber MD
}

\section{Abstract}

Background: Antimicrobial resistance is an important public health issue globally and in Canada. To understand the current state of antimicrobial stewardship programs in Ontario health care facilities, Public Health Ontario conducted a voluntary survey of hospitals in the province.

Methods: The Ontario Antimicrobial Stewardship Program Landscape Survey was distributed online to hospitals, targeting front-line antimicrobial stewardship clinicians. The survey was open for 5 weeks in fall 2016. We used email and telephone reminders to encourage response. We performed descriptive and inferential statistical analyses at an aggregate level and by hospital type. Mental health and ambulatory sites were excluded.

Results: The response rate was $74.0 \%$ (97/131 organizations). Of the 97,90 (93\%) reported having a formal antimicrobial stewardship program or were in the process of implementing a formal program. Just over half (50 [56\%]) identified appropriate antibiotic use as part of the organization's quality-improvement plan, strategic goal or priority. Half (45 [50\%]) of programs did not have designated resources; those that did are underresourced with respect to physician and pharmacist staffing. The scope of implementation of program strategies was variable. Fifty hospitals (56\%) reported tracking antimicrobial expenditures, $47(52 \%)$ reported tracking defined daily dose, and 35 (39\%) reported tracking days of therapy.

Interpretation: Most Ontario hospitals have a formal antimicrobial stewardship program, but there are opportunities for improvement. Future efforts should increase the priority of and improve resource allocation for antimicrobial stewardship programs so that programs can continue to grow in scope and impact.

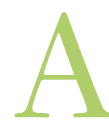

ntimicrobial resistance is an important public health issue and has been highlighted as a serious threat to human health. ${ }^{1,2}$ Globally, 700000 deaths annually are attributed to infections caused by antimicrobial-resistant organisms, and this number is expected to grow. ${ }^{3}$ The burden of antimicrobial resistance is also evident in Canada, including Ontario, with rising rates of methicillin-resistant Staphylococcus aureus, vancomycin-resistant Enterococcus bacteremia and Enterobacteriaceae resistant to fluoroquinolones and cephalosporins. ${ }^{4}$ As such, antimicrobial resistance has been identified as an area of substantial concern for the government of Canada, the Ontario Ministry of Health and Long-Term Care and Public Health Ontario. ${ }^{5}$ Antimicrobial stewardship can be defined as coordinated interventions designed to improve and measure the appropriate use of antimicrobial agents in terms of drug selection, dosing, duration of treatment and route of administration. ${ }^{6}$ Antimicrobial stewardship programs aim to optimize clinical outcomes related to antimicrobial use while minimizing toxicity and other adverse events as well as reduce antimicrobial resistance in individual patients and in the population by limiting selective pressure on microbial populations through improved prescribing.

Since 2013, antimicrobial stewardship has been an Accreditation Canada Required Organizational Practice for inpatient health care institutions. ${ }^{7}$ To help build, grow and enhance local antimicrobial stewardship programs, Public Health Ontario compiled a comprehensive list of 32 antimicrobial stewardship strategies (www.publichealthontario.ca/asp). The strategies are organized into 5 categories: prescribing guid-

\section{Competing interests: None declared.}

This article has been peer reviewed.

Correspondence to: Valerie Leung, valerie.leung @oahpp.ca CMAJ Open 2018. DOI:10.9778/cmajo.20170111 
ance, clinical, microbiology-related, structural/process and formulary-related. A subset of these strategies also corresponds to an evidence-based framework to implement antimicrobial stewardship programs released by the Infectious Diseases Society of America/Society for Healthcare Epidemiology of America (IDSA/SHEA) in 2016, with several strong recommendations for the general adult inpatient population. ${ }^{8}$ Previous provincial surveys showed that antimicrobial stewardship programs were "rare" in Ontario hospitals in 2007, whereas the proportion of hospitals with such programs was $32 \%$ in 2011; there still exists substantial opportunity for improvement in both the scope and maturity of hospital antimicrobial stewardship programs. ${ }^{9-11}$ To gain an understanding of the current state of these programs, Public Health Ontario conducted a voluntary survey of hospitals.

\section{Methods}

\section{Survey design}

The Ontario Antimicrobial Stewardship Program Landscape Survey was developed by the antimicrobial stewardship program team at Public Health Ontario based on previous surveys of hospital antimicrobial stewardship programs, ${ }^{9-11}$ an environmental scan of program elements in acute care settings and input from stakeholders. The aim was to include a comprehensive list of structural and strategic program elements regardless of evidence to support their impact on prescribing or clinical outcomes. The survey was piloted with selected people involved in hospital antimicrobial stewardship programs (e.g., pharmacists, program leads) and was refined based on their feedback before dissemination.

The survey had 29 adaptive questions to simplify the questionnaire (illustrated in Appendix 1, available at www.cmajopen. $\mathrm{ca} /$ content/6/1/E71/supp1/DC1). Definitions of each strategy were included in the survey, and respondents were directed to the Web site for further details (e.g., description, associated metrics, references). Efforts were made to resolve duplicate and incomplete responses by contacting the organization for clarification. Hospital type was classified as per Ontario Hospital Association definitions, ${ }^{12}$ and multisite organizations were classified by the largest hospital type.

\section{Survey eligibility and distribution}

The online survey, open for 5 weeks (Sept. 19-Oct. 24, 2016), was administered through FluidSurveys (www.fluidsurveys. com). Respondents could also complete the questionnaire on paper and submit by fax.

All hospital organizations in Ontario were eligible for inclusion except those categorized by the Ontario Hospital Association as providing primarily mental health or ambulatory services, since antimicrobial stewardship programs are not required by Accreditation Canada for these types of organizations. We created a targeted distribution list using information from the Ontario Ministry of Health and LongTerm Care's hospital organization list, Public Health Ontario's Infection Prevention and Control regional teams and stakeholder relationship management list, and the distri- bution list of the Antimicrobial Stewardship Hospital Pharmacists of Ontario Network. The survey was distributed to all hospitals, addressed to the person most responsible for antimicrobial stewardship in the organization (e.g., antimicrobial stewardship pharmacist or physician) via email with the instruction that the survey should be completed with 1 response per organization unless there were multiple sites and submission of site-specific responses was desired.

To encourage participation, we sent targeted emails to organizations that did not initially respond to the survey, followed by a telephone call reminder 2 weeks afterward.

There were no monetary incentives to participate.

\section{Statistical analysis}

We calculated descriptive statistics using Microsoft Excel 2010 version 14.0.6024.1000. We performed statistical comparisons for key structural (program implementation, program maturity $\geq 3 \mathrm{yr}$, funding or resources, and antimicrobial use as organizational priority) and strategic elements that align with IDSA/SHEA strong recommendations (therapeutic drug monitoring, intravenous to oral conversion, formulary restriction, prospective audit and feedback) using the Fisher exact test and SAS Enterprise Guide version 7.1 (SAS Institute). The methodology of the survey has been reported according to criteria specific to online surveys. ${ }^{13}$

\section{Ethics approval}

The survey was approved by Public Health Ontario's Ethics Review Board.

\section{Resullts}

\section{Hospital characteristics}

Of the 131 eligible hospital organizations, 97 responded, for a response rate of $74.0 \%$. Most organizations (59/97) did not have multiple sites. Eight multisite organizations submitted site-specific responses with no overlap with the other site(s). Table 1 shows characteristics of the responding organizations. The survey was completed primarily by physicians or pharmacists directly involved in antimicrobial stewardship activities. The response rate was lowest for small community hospitals $(61 \%)$ and highest for acute teaching hospitals $(91 \%)$.

Of the 97 organizations, 85 (88\%) reported having a formal antimicrobial stewardship program, $5(5 \%)$ were in the process of implementing a formal program, and $7(7 \%)$ did not have a formal program. Table 2 shows the presence of formal programs by hospital type. There was no difference in program implementation between hospital types $(p=0.2)$. However, there was significant variation in the presence of a mature program, with 56 formal programs $(62 \%)$ having been established in 2013 or earlier versus after $2013(p=0.004)$; the vast majority of these were in acute teaching or large community hospitals.

\section{Program structural elements}

Almost all of the 90 hospital organizations with or in the process of implementing a formal antimicrobial stewardship 


\begin{tabular}{|c|c|c|}
\hline Characteristic & $\begin{array}{l}\text { No. }(\%) \text { of } \\
\text { responding } \\
\text { hospitals } \\
n=97\end{array}$ & $\begin{array}{l}\text { Total no. }(\%) \\
\text { in Ontario* } \\
n=131\end{array}$ \\
\hline \multicolumn{3}{|l|}{ Hospital type } \\
\hline Acute teaching & $15(15.0)$ & $16(12.2)$ \\
\hline Large community & $44(45.4)$ & $57(43.5)$ \\
\hline Small community & $27(27.8)$ & $44(33.6)$ \\
\hline $\begin{array}{l}\text { Complex continuing care/ } \\
\text { inpatient rehabilitation }\end{array}$ & $11(11.3)$ & $14(10.7)$ \\
\hline \multicolumn{3}{|l|}{ Region† } \\
\hline North & $22(22.7)$ & $36(27.5)$ \\
\hline West & $11(11.3)$ & $19(14.5)$ \\
\hline Central-West & $14(14.4)$ & $18(13.7)$ \\
\hline Central & $31(32.0)$ & $34(26.0)$ \\
\hline East & $19(19.6)$ & $24(18.3)$ \\
\hline$>1$ site & $38(39.2)$ & - \\
\hline \multicolumn{3}{|l|}{ No. of inpatient beds } \\
\hline$>200$ & $46(47.4)$ & - \\
\hline $100-200$ & $12(12.4)$ & - \\
\hline $51-99$ & $19(19.6)$ & - \\
\hline$\leq 50$ & $20(20.6)$ & - \\
\hline \multicolumn{3}{|c|}{$\begin{array}{l}\text { *Hospital organizations excluding those providing primarily mental health or } \\
\text { ambulatory services. } \\
\text { †Defined according to Public Health Ontario regional Infection Prevention and } \\
\text { Control office boundaries. }{ }^{11}\end{array}$} \\
\hline
\end{tabular}

program had a multidisciplinary antimicrobial stewardship committee (74 [82\%]) and physician (78 [87\%]) and pharmacist $(87$ [97\%]) champions. Over two-thirds $(63$ [70\%]) had guidance documents that help direct program development. Over half (46 [56\%]) identified appropriate antibiotic use as part of their organizational quality-improvement plan, strategic goal or priority; there was no difference between hospital types $(p=0.9)$.

Half (45 [50\%]) of the 90 organizations with or in the process of implementing a formal antimicrobial stewardship program reported having designated funding/resources for their program. More acute teaching hospitals than other hospital types reported having designated resources $(p<$ 0.001 ). Only 3 small community and 2 complex continuing care/rehabilitation hospitals reported having designated resources; 2 of these had resources specifically allocated for an antimicrobial stewardship physician and/or pharmacist. Resource allocation for physicians and pharmacists at acute teaching and large community hospitals is presented in Table 3. Small community hospitals reported an average of 0.006 pharmacist full-time equivalents (FTEs) and 0 physician FTEs; the corresponding values for complex continuing care/rehabilitation hospitals were 0.55 and 0.15 . Few organizations $(5 / 45[11 \%])$ reported having dedicated resources for information technology professionals or other administrative/program support.

\section{Implementation of antimicrobial stewardship strategies}

Table 4 shows the frequency of implementation of antimicrobial stewardship strategies in Ontario hospitals as of 2016. The most frequently implemented strategies were therapeutic drug monitoring (83 hospitals [86\%]), antibiograms (79 $[81 \%])$ and computerized automatic stop orders (79 [81\%]). Least commonly implemented strategies included clinical decision support systems/computerized physician order entry (12 [12\%]), checklists (14 [14\%]) and improved antimicrobial documentation (22 [23\%]). With respect to implementation of strategies most closely aligned with IDSA/SHEA recommendations, there were no differences between hospital types for formulary restriction $(p=0.1)$, formulary restriction with preauthorization $(p=0.2)$, intravenous to oral conversion $(p=$ $0.1)$ or therapeutic drug monitoring $(p=0.7)$. Prospective audit and feedback implementation, however, did vary across hospital types, with more acute teaching and large community hospitals than other hospital types reporting implementation of this approach $(p<0.001)$.

\section{Measuring program impact}

Fifty hospital organizations (56\%) reported measuring antimicrobial expenditures, 47 (52\%) reported tracking defined daily dose, and 35 (39\%) reported tracking days of therapy.

\begin{tabular}{|c|c|c|c|}
\hline Hospital type & $\begin{array}{l}\text { No. }(\%) \text { with } \\
\text { formal program }\end{array}$ & $\begin{array}{l}\text { No. }(\%) \text { in } \\
\text { process of } \\
\text { implementing } \\
\text { formal program }\end{array}$ & $\begin{array}{c}\text { No. }(\%) \\
\text { without formal } \\
\text { program }\end{array}$ \\
\hline Acute teaching $(n=15)$ & $14(93)$ & $0(0)$ & $1(7)$ \\
\hline Large community $(n=44)$ & $41(93)$ & $0(0)$ & $3(7)$ \\
\hline Small community $(n=27)$ & $21(78)$ & $4(15)$ & $2(7)$ \\
\hline $\begin{array}{l}\text { Complex continuing care/ } \\
\text { inpatient rehabilitation } \\
(n=11)\end{array}$ & $9(82)$ & $1(9)$ & $1(9)$ \\
\hline Total $(n=97)$ & $85(88)$ & $5(5)$ & $7(7)$ \\
\hline
\end{tabular}




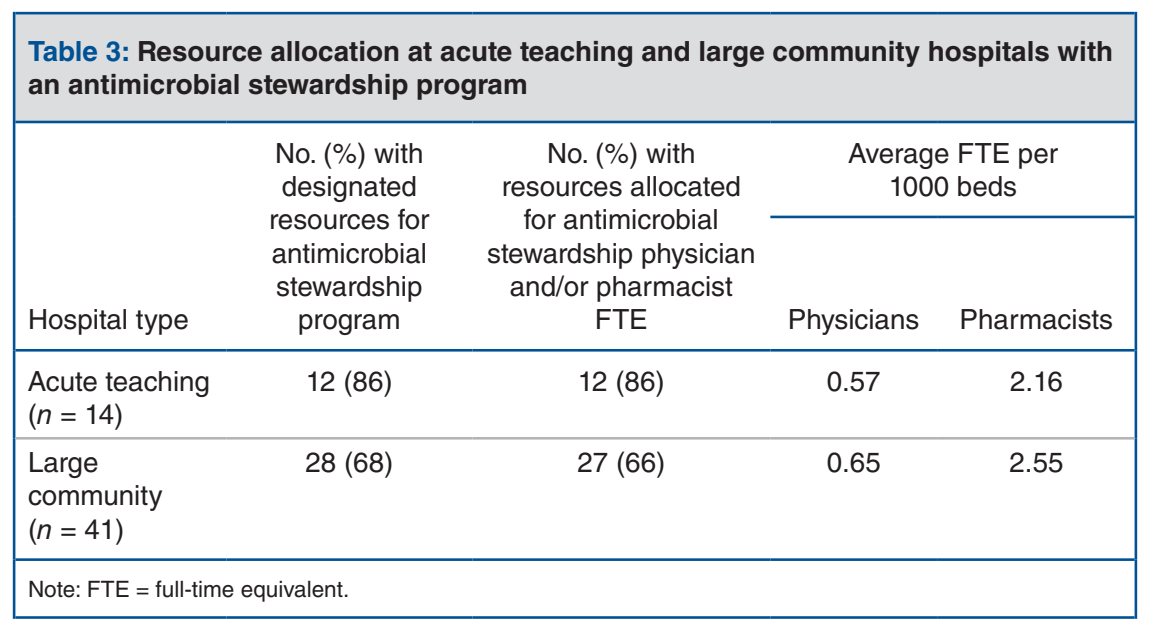

Fifty-one (57\%) and 40 (44\%) reported tracking program interventions and acceptance rates, respectively. Most hospitals reported including tracking of antimicrobial resistance (69 [77\%]) and rates of Clostridium difficile infection $(67[74 \%])$ in their antimicrobial stewardship activities.

\section{Interpretation}

The results of this detailed survey provide insight into the current state of antimicrobial stewardship programs in Ontario hospitals and areas for growth. Elevating the priority and visibility of such programs and optimizing resource allocation are 2 such opportunities: $56 \%$ of hospitals reported that appropriate antibiotic use is part of their organizational quality-improvement plan, strategic goal or priority, and $49 \%$ had specific resources allocated for antimicrobial stewardship physician(s) and/or pharmacist(s).

Organizational commitment to improving antimicrobial use and to antimicrobial stewardship resources in this study was similar to that in a recent national survey of over 4000 US acute care hospitals by the Centers for Disease Control and Prevention (CDC), ${ }^{14}$ which showed that $52.6 \%$ of hospitals had a written statement of support and $31.7 \%$ had salary support. These results highlight the importance of leadership commitment in building robust antimicrobial stewardship programs: both written statement of support and salary support independently predicted implementation of all 7 CDC core elements of hospital antimicrobial stewardship programs. ${ }^{1}$ Our survey provided additional information regarding the level of resource allocation for antimicrobial stewardship physician(s) and pharmacist(s). In 2016, the Association of Medical Microbiology and Infectious Disease Canada released business case recommendations for inpatient antimicrobial stewardship programs in acute care, cancer care, and rehabilitation and complex continuing care. ${ }^{15}$ For larger institutions (acute teaching, large community), the recommendation is 1.0 physician and 3.0 pharmacist FTEs per 1000 beds. In the current study, acute teaching hospitals with designated resources reported an average of 0.57 physician and 2.16 pharmacist FTEs per 1000 beds, and large community hospitals with designated resources reported an average of 0.65 physician and 2.55 pharmacist FTEs per 1000 beds. In addition, the Association of Medical Microbiology and Infectious Disease Canada recommends designated resources for administrative/program support and data analysis; however, few organizations in this survey reported having such resources. Accordingly, there is opportunity for improvement in resource allocation for hospital antimicrobial stewardship programs in Ontario.

All respondents reported implementing at least 1 stewardship strategy, whether or not they had a formal antimicrobial stewardship program; however, the overall scope of implementation varied. It is encouraging that implementation of impactful strategies such as prospective audit and feedback ${ }^{8}$ is now in place in most $(65 \%)$ of the responding organizations. This compares favourably with the proportion reported in the CDC survey, $63 \% .{ }^{14}$ Conversely, formulary restriction is less commonly implemented in Ontario hospitals (54\% and 29\% without and with preauthorization, respectively). It is likely that many organizations prefer prospective audit and feedback, as this approach is more collegial and provides an opportunity for prescriber engagement and education, aspects that are lacking with a restrictive strategy. Consistent with the CDC survey ${ }_{14}^{14}$ measurement of program impact is an area for further development. Tracking and reporting antibiotic use is considered a core component of hospital antimicrobial stewardship programs, ${ }^{1}$ yet a substantial proportion of hospitals are not reporting data on drug use. The proportions that reported tracking defined daily dose (51\%), antimicrobial expenditures $(56 \%)$ and days of therapy (39\%) were similar to those in the CDC survey ${ }^{14}(60 \%$ for tracking purchase data or defined daily dose, and $37 \%$ for measuring days of therapy).

Hospital antimicrobial stewardship programs in Ontario need more infrastructure and support for measurement of local program impact. This is also true from a provincial perspective, because to effectively plan, evaluate and strengthen antimicrobial stewardship programs on a systems level, the ability to compare and benchmark antibiotic use is critical. ${ }^{16,17}$ Although a coordinated system for synthesizing and benchmarking data on hospital antimicrobial use in Ontario is not 
Table 4: Frequency of implementation of antimicrobial stewardship strategies

\begin{tabular}{|c|c|c|c|c|c|}
\hline \multirow[b]{2}{*}{ Strategy } & \multicolumn{5}{|c|}{ No. $(\%)$ of hospitals } \\
\hline & $\begin{array}{l}\text { Acute teaching } \\
\qquad n=15\end{array}$ & $\begin{array}{l}\text { Large } \\
\text { community } \\
n=44\end{array}$ & $\begin{array}{c}\text { Small } \\
\text { community } \\
n=27\end{array}$ & $\begin{array}{c}\text { Complex } \\
\text { continuing } \\
\text { care/inpatient } \\
\text { rehabilitation } \\
\quad n=11\end{array}$ & $\begin{array}{l}\text { Overall } \\
n=97\end{array}$ \\
\hline \multicolumn{6}{|l|}{ Prescribing guidance } \\
\hline Intravenous to oral conversion & $11(73)$ & $36(82)$ & $17(63)$ & $5(45)$ & $69(71)$ \\
\hline $\begin{array}{l}\text { Disease-specific treatment guidelines/pathways/ } \\
\text { algorithms and/or associated order forms }\end{array}$ & $10(67)$ & $36(82)$ & $15(56)$ & $8(73)$ & $69(71)$ \\
\hline Empiric antibiotic prescribing guidelines & $12(80)$ & $29(66)$ & $13(48)$ & $7(64)$ & $61(63)$ \\
\hline Prescriber education & $13(87)$ & $30(68)$ & $9(33)$ & $5(45)$ & $57(59)$ \\
\hline $\begin{array}{l}\text { Facilitation of appropriate and timely antimicrobial } \\
\text { administration in severe sepsis/septic shock }\end{array}$ & $7(47)$ & $24(54)$ & $9(33)$ & $1(9)$ & $41(42)$ \\
\hline $\begin{array}{l}\text { Clinical decision support systems/computerized } \\
\text { physician order entry }\end{array}$ & $5(33)$ & $4(9)$ & $2(7)$ & $1(9)$ & $12(12)$ \\
\hline \multicolumn{6}{|l|}{ Clinical } \\
\hline Therapeutic drug monitoring (with feedback) & $12(80)$ & $39(89)$ & $23(85)$ & $9(82)$ & $83(86)$ \\
\hline Dosage optimization & $12(80)$ & $37(84)$ & $17(63)$ & $6(54)$ & $72(74)$ \\
\hline Deescalation and streamlining & $11(73)$ & $31(70)$ & $16(59)$ & $5(45)$ & $63(65)$ \\
\hline Prospective audit with intervention and feedback & $12(80)$ & $36(82)$ & $9(33)$ & $6(54)$ & $63(65)$ \\
\hline $\begin{array}{l}\text { Targeted review of redundant therapy or } \\
\text { therapeutic duplication }\end{array}$ & $5(33)$ & $31(70)$ & $18(67)$ & $4(36)$ & $58(60)$ \\
\hline $\begin{array}{l}\text { Identification of inappropriate pathogen/ } \\
\text { antimicrobial combinations ("bug-drug } \\
\text { mismatch") }\end{array}$ & $7(47)$ & $30(68)$ & $14(52)$ & $7(64)$ & $58(60)$ \\
\hline $\begin{array}{l}\text { Targeted review of patients with Clostridium } \\
\text { difficile infection }\end{array}$ & $5(33)$ & $34(77)$ & $11(41)$ & $6(54)$ & $56(58)$ \\
\hline Preventing treatment of noninfectious conditions & $6(40)$ & $26(59)$ & $7(26)$ & $3(27)$ & $42(43)$ \\
\hline $\begin{array}{l}\text { Targeted review of patients with bacteremia/ } \\
\text { fungemia }\end{array}$ & $7(47)$ & $24(54)$ & $7(26)$ & $2(18)$ & $40(41)$ \\
\hline $\begin{array}{l}\text { Scheduled antimicrobial reassessments } \\
\text { ("antibiotic time outs") }\end{array}$ & $4(27)$ & $16(36)$ & $7(26)$ & $2(18)$ & $29(30)$ \\
\hline \multicolumn{6}{|l|}{ Microbiology-related } \\
\hline Antibiograms & $14(93)$ & $41(93)$ & $19(70)$ & $5(45)$ & $79(81)$ \\
\hline Reporting of cascading microbiology susceptibility & $12(80)$ & $35(80)$ & $4(15)$ & $2(18)$ & $53(55)$ \\
\hline Reporting of strategic microbiology results & $12(80)$ & $31(70)$ & $7(26)$ & $3(27)$ & $53(55)$ \\
\hline $\begin{array}{l}\text { Promotion of timely and appropriate microbiologic } \\
\text { sampling }\end{array}$ & $10(67)$ & $27(61)$ & $12(44)$ & $2(18)$ & $51(52)$ \\
\hline Improved diagnostics & $12(80)$ & $25(57)$ & $8(30)$ & $2(18)$ & $47(48)$ \\
\hline \multicolumn{6}{|l|}{ Structural/process-related } \\
\hline Automatic stop orders & $8(53)$ & $39(89)$ & $24(89)$ & $7(64)$ & $78(80)$ \\
\hline Drug use evaluation/medication use evaluation & $9(60)$ & $23(52)$ & $11(41)$ & $7(64)$ & $50(52)$ \\
\hline Optimization of surgical antibiotic prophylaxis & $13(87)$ & $27(61)$ & $5(18)$ & $1(9)$ & $46(47)$ \\
\hline General antimicrobial order forms & $1(7)$ & $14(32)$ & $8(30)$ & $4(36)$ & $27(28)$ \\
\hline Systematic antibiotic allergy verification & $1(7)$ & $15(34)$ & $3(11)$ & $6(54)$ & $25(26)$ \\
\hline Improved antimicrobial documentation & $2(13)$ & $10(23)$ & $6(22)$ & $4(36)$ & $22(23)$ \\
\hline Checklists & $4(27)$ & $5(11)$ & $1(4)$ & $4(36)$ & $14(14)$ \\
\hline \multicolumn{6}{|l|}{ Formulary-related } \\
\hline Formulary review/streamlining & $10(67)$ & $35(80)$ & $23(85)$ & $5(45)$ & $73(75)$ \\
\hline $\begin{array}{l}\text { Formulary automatic substitution/therapeutic } \\
\text { interchange policies }\end{array}$ & $10(67)$ & $37(84)$ & $18(67)$ & $4(36)$ & $69(71)$ \\
\hline Formulary restriction & $11(73)$ & $26(59)$ & $11(41)$ & $4(36)$ & $52(54)$ \\
\hline Formulary restriction with preauthorization & $6(40)$ & $15(34)$ & $4(15)$ & $3(27)$ & $28(29)$ \\
\hline
\end{tabular}


yet in place, the current variation in antimicrobial use measurement and requirement for risk adjustment needs to be addressed to support a region-wide antibiotic use surveillance program. For these reasons, policy actions to strengthen individual hospital program measurement along with efforts to standardize and improve data quality are needed.

\section{Strengths and limitations}

A key strength of this voluntary survey is the overall response rate of $74 \%$, within the range of acceptable response rates $(50 \%-75 \%) .{ }^{18}$ However, several limitations should be noted. First, responses were self-reported, and it was not feasible to validate survey responses against actual elements of antimicrobial stewardship programs at each hospital. The fact that small community hospitals were underrepresented introduced potential bias toward organizations with formal and potentially more well-established antimicrobial stewardship programs in the overall results. Furthermore, because the data were at the organizational level, any variation in strategy implementation at different sites within organizations was not captured. In addition, since Public Health Ontario's 32 antimicrobial stewardship strategies are not mutually exclusive, some overlap, and differences in interpretation should be expected. One example would be degree of implementation for allergy verification: although many organizations may have an established process for allergy status clarification and documentation, some may not indicate that they systematically implemented this strategy if they were contemplating more advanced techniques (e.g., penicillin skin testing). Furthermore, our survey does not provide insight into the extent or fidelity of strategy implementation. For example, prospective audit and feedback can be operationalized in various ways, from rotating between services to reviewing all inpatients. Given the discrepancy in resource allocation between hospital types and the need to further describe both the scope and breadth of implementation of antimicrobial stewardship programs, future research should address the impact of resources on the extent or fidelity of program implementation and evaluate outcomes at both the patient and population levels. Finally, we could not determine the impact of the antimicrobial stewardship programs. Work is underway to explore the relation between specific program structural and strategic elements and antimicrobial use in a subset of Ontario hospitals.

\section{Conclusion}

Our findings suggest that, although most Ontario hospitals have established a foundation for their antimicrobial stewardship program, there remain significant opportunities for improvement, particularly in small hospitals and complex continuing care/rehabilitation organizations. In addition, senior leadership sponsorship, including support for measurement of program impact, is required to advance antimicrobial stewardship programs. Future efforts should focus on optimizing resource allocation so that programs can continue to grow in scope and impact.

\section{References}

1. Core elements of hospital antibiotic stewardship programs. Atlanta: Centers for Disease Control and Prevention; 2014. Available: https://www.cdc.gov/ getsmart/healthcare/implementation/core-elements.html (accessed 2016 Dec. 16).

2. Global action plan on antimicrobial resistance. Geneva: World Health Organization; 2015. Available: http://apps.who.int/iris/bitstream/10665/193736/1/ 9789241509763 eng.pdf?ua=1 (accessed 2017 Aug. 9)

3. Review on Antimicrobial Resistance. Antimicrobial resistance: tackling a crisis for the bealth and wealth of nations. London (UK): Creative Commons; 2014. Available: https://amr-review.org/sites/default/files/AMR\%20Review\%20Paper\%20 -\%20Tackling\%20a\%20crisis\%20for\%20the\%20health\%20and\%20wealth\% 20of\%20nations_1.pdf (accessed 2017 Aug. 9).

4. Ontario Agency for Health Protection and Promotion (Public Health Ontario) and Institute for Quality Management in Healthcare. Antimicrobial resistance in common hospital pathogens in Ontario: annual laboratory and hospital survey report 2015. Toronto: Queen's Printer for Ontario; 2017. Available: www.publichealthontario.ca/en/eRepository/ARO_Survey_Report_2015.pdf (accessed 2017 Aug. 9).

5. Ontario Agency for Health Protection and Promotion (Public Health Ontario). Antimicrobial resistance: a public bealth threat. Toronto: Queen's Printer for Ontario; 2016. Available: https://www.publichealthontario.ca/en/ eRepository/OHP_infog_AntimicrobialResistance_2016.pdf (accessed 2017 Aug. 9).

6. Society for Healthcare Epidemiology of America, Infectious Diseases Society of America and Pediatric Infectious Diseases Society. Policy statement on antimicrobial stewardship by the Society for Healthcare Epidemiology of America (SHEA), the Infectious Diseases Society of America (IDSA), and the Pediatric Infectious Diseases Society (PIDS). Infect Control Hosp Epidemiol 2012;33:322-7.

7. Required Organizational Practices: handbook 2016. Ottawa: Accreditation Canada; 2015.

8. Barlam TF, Cosgrove SE, Abbo LM, et al. Implementing an antibiotic stewardship program: guidelines by the Infectious Diseases Society of America and the Society for Healthcare Epidemiology of America. Clin Infect Dis 2016;62: e5 $1-77$.

9. Ontario antimicrobial stewardship survey summary. Toronto: Institute for Safe Medication Practices Canada; 2007. Available: https://www.ismp-canada.org/ abx/downloads/Ont_Abx_Stewardship_Survey_Summary.pdf (accessed 2017 Aug. 9).

10. Johanson C, Raybardhan S, Hogg A, et al. Advancing a provincial program for antimicrobial stewardship in Ontario [poster]. Infection Prevention and Control Canada conference; 2015 June 14-17; Victoria.

11. Reddy P, Nisbet C, Van Horne L, et al. Early development of a provincial antimicrobial stewardship support model: a needs assessment survey of Ontario hospitals [poster]. IDWeek conference; 2013 Oct. 2-6; San Francisco.

12. Hospital report 2007: acute care. Ottawa: Canadian Institute for Health Information, Government of Ontario, Ontario Hospital Association and Hospital Report Research Collaborative; 2007. Available: https://secure.cihi.ca/free_ products/OHA_Acute07_EN_final_secure.pdf (accessed 2017 Aug. 9).

13. Eysenbach G. Improving the quality of web surveys: the checklist for reporting results of internet e-surveys (CHERRIES). 7 Med Internet Res 2004;6:e34.

14. Pollack LA, van Santen KL, Weiner LM, et al. Antibiotic stewardship programs in U.S. acute care hospitals: findings from the 2014 National Healthcare Safety Network Annual Hospital Survey. Clin Infect Dis 2016;63:443-9.

15. How to build a case for an inpatient antimicrobial stewardship program [business case]. Ottawa: Association of Medical Microbiology and Infectious Disease Canada; 2016. Available: https://www.ammi.ca/?ID=126 (accessed 2017 Jan. 10).

16. Ibrahim OM, Polk RE. Antimicrobial use metrics and benchmarking to improve stewardship outcomes: methodology, opportunities, and challenges. Infect Dis Clin North Am 2014;28:195-214.

17. Septimus E. Antimicrobial stewardship - qualitative and quantitative outcomes: the role of measurement. Curr Infect Dis Rep 2014;16:433.

18. Draugalis JR, Coons SJ, Plaza CM. Best practices for survey research reports: a synopsis for authors and reviewers. Am F Pharm Educ 2008;72:11.

Affiliations: Public Health Ontario (Leung, Wu, Langford, Garber); Department of Medicine (Garber), University of Toronto, Toronto, Ont.

Contributors: Valerie Leung, Julie Wu and Bradley Langford collected the data. Valerie Leung drafted the manuscript. All of the authors contributed to study conception and design, and data analysis and interpretation, critically revised the manuscript for important intellectual content, gave final approval of the version to be published and agreed to be accountable for all aspects of the work.

Supplemental information: For reviewer comments and the original submission of this manuscript, please see www.cmajopen.ca/content/6/1/ E71/suppl/DC1 